\title{
Driving Pressure: Clinical Applications and Implications in the Intensive Care Units
}

\author{
Jithin K. Sreedharan, Jaber Saud Alqahtani \\ Department of Respiratory Care, Prince Sultan Military College of Health Sciences, Dhahran Saudi Arabia
}

\section{Abstract}

Acute respiratory distress syndrome (ARDS) is considered a frequent and serious lung disease that is continuously linked with an increase in both morbidity and mortality. Mechanical ventilation (MV) is considered as the gold standard therapy in the management of ARDS; although MV support is lifesaving, it is also associated with potentially harmful threats such as ventilator-induced lung injury (VILI). It is understood from the physiological background itself that VILI has a considerable impact on the prognosis of a patient. Therefore, the current studies show that focusing on key therapeutic elements causing over-distension of the available lung units is more imperative for indicating further damage than how much pressure is used to ventilate. In the past two decades, there has been an increasing trend toward using driving pressure (DP) in the management of ARDS patients in intensive care units (ICUs). Recent studies propose that measuring DP in ARDS patients, in addition to the other respiratory mechanics measurements, may support selecting and customizing appropriate ventilator parameters, which, in turn, improves patient outcomes and decreases mortality rate. Therefore, this review is intended to outline the physiological meaning of DP, the clinical measurement and application of DP and factors limiting DP. Furthermore, measuring DP in non-ARDS patients and recent clinical evidence for the use of DP in the ICUs will be discussed in detail.

Keywords: Acute respiratory distress syndrome, driving pressure, lung injury, mechanical ventilation, ventilator-induced lung injury

\section{INTRODUCTION}

Acute respiratory distress syndrome (ARDS) is a global disease that is described as a rapid onset of severe hypoxic respiratory failure and changes in respiratory system mechanics. There are three main abnormal physiological alterations as ARDS progresses, which are severe hypoxemia, inability to wash out the carbon dioxide $\left(\mathrm{CO}_{2}\right)$, and intact reduction in the available lung units to ventilate. The prevalence of ARDS in critical care units impacts up to $23 \%$ of patients who are mechanically ventilated. ${ }^{[1]}$ Loss of aerated lung tissue due to collapse, pulmonary flooding or consolidation, and increased permeability of the pulmonary vasculatures are associated with ARDS. ${ }^{[2]}$ Indeed, these alterations in the lung units put the patient at high risk of ventilatorinduced lung injury (VILI) either by atelectrauma or by overdistention. ${ }^{[3]}$ Recently, a multinational observational study called "lung safe study" attempted to find the incidence of ARDS in the Intensive Care Unit (ICU), and the results of this study revealed that the overall mortality rate caused by ARDS ranged from $34.9 \%$ to $46.1 \%$. $^{[1]}$

\begin{tabular}{|l|l|}
\hline \multicolumn{2}{|c|}{ Access this article online } \\
\hline Quick Response Code: & Website: \\
& www.ijrconline.org \\
\cline { 2 - 2 } & \\
\end{tabular}

Use of mechanical ventilation (MV) support is crucial in the management of ARDS patients and largely affects the survival rate. Nevertheless, MV may cause VILI that can aggravate lung injury from the original cause of ARDS such as multiorgan dysfunction. ${ }^{[4-9]}$ VILI is characterized by a chaotic inflammatory response along with diffuse systemic involvement (biotrauma) driven by pressure (barotrauma) and volume (volutrauma) overload. ${ }^{[10]}$ Since ARDSNet trials published in the year 2000, there have been tremendous trials that intended to identify ventilation strategies to reduce or prevent VILI in ARDS patients. Subsequently, it has been believed that lowering the tidal volume $\left(\mathrm{V}_{\mathrm{T}}\right)$ to $6 \mathrm{ml} / \mathrm{kg}$ of predicted body weight (PBW) improved the outcome and reduced the incidence of VILI. ${ }^{[1]}$ However, there is a growing body of evidence that shows patients with limited aerated lung units available

Address for correspondence: Jithin K. Sreedharan, Department of Respiratory Care, Prince Sultan Military College of Health Sciences, Dhahran, P.0. Box 33048, Dammam 31448 Saudi Arabia, E-mail: jithinksree@psmchs.edu.sa

This is an open access journal, and articles are distributed under the terms of the Creative Commons Attribution-NonCommercial-ShareAlike 4.0 License, which allows others to remix, tweak, and build upon the work non-commercially, as long as appropriate credit is given and the new creations are licensed under the identical terms.

For reprints contact: reprints@medknow.com

How to cite this article: Sreedharan JK, Alqahtani JS. Driving pressure: Clinical applications and implications in the intensive care units. Indian J Respir Care 2018;7:62-6. 
for ventilation can still be affected by VILI although $\mathrm{V}_{\mathrm{T}}$ is $6 \mathrm{ml} / \mathrm{kg}$ of PBW. ${ }^{[12]}$ In addition, plateau pressure and positive end-expiratory pressure (PEEP) also have a substantial role in reducing or inducing the mechanical stress in the lung. ${ }^{[4,8]}$ There has been evidence to limit $\mathrm{V}_{\mathrm{T}}$ to the PBW to protect the lungs by targeting the $\mathrm{V}_{\mathrm{T}}$ to lung size. However, the proportion of the lung units available for ventilation is significantly reduced in ARDS patients and this reduction is reflected by decreased respiratory system compliance $\left(\mathrm{C}_{\mathrm{R}} \mathrm{S}\right) \cdot{ }^{[12,13]}$

In the past 3 years, driving pressure (DP) has been a major area of interest within the ARDS management after the Amato et al. study. ${ }^{[14]}$ This study had a multilevel mediation analysis that used data from ARDS patients who enrolled in previously reported randomized and controlled trials. Relatively, low levels of DP were found to be significantly associated with survival in ARDS patients, whereas $\mathrm{V}_{\mathrm{T}}$ and PEEP were not independently associated with survival. Since the concept of DP has received considerable critical attention in the literature, this review is intended to discuss the physiological background of DP, clinical applications and limitations of DP in ARDS patients, and current clinical evidence pertinent to the outcome.

\section{Physiological Background of Driving Pressure}

Amato et al. suggested that the causation of VILI could be due to the cyclic recruitment-de recruitment and tidal hyperinflation of the aerated lung units in ARDS due to an increase in pressure during MV ${ }^{[14]}$ This difference in the applied pressure is known as DP. DP is the difference between the plateau pressure $(\mathrm{Ppl})$ and PEEP. ${ }^{[14,15]}$

$\mathrm{DP}=\mathrm{Ppl}-\mathrm{PEEP}$

The static compliance of the respiratory system $\left(\mathrm{C}_{\mathrm{RS}}\right)$ is calculated as a ratio between $\mathrm{V}_{\mathrm{T}}$ and the pressure change (DP). Thus,

$\mathrm{C}_{\mathrm{RS}}=\mathrm{V}_{\mathrm{T}} / \mathrm{Ppl}-\mathrm{PEEP}=\mathrm{V}_{\mathrm{T}} / \mathrm{DP}$

The DP can be written as the ratio between $\mathrm{V}_{\mathrm{T}}$ and the static compliance of the respiratory system resembling the lung and chest wall elastance. ${ }^{[16]}$

$\mathrm{DP}=\mathrm{V}_{\mathrm{T}} / \mathrm{C}_{\mathrm{RS}}$

Thus, in simple mathematics, DP is the proportion between the $\mathrm{V}_{\mathrm{T}}$ and $\mathrm{C}_{\mathrm{RS}}$ of the patient. This ratio of $\mathrm{C}_{\mathrm{RS}}$ could be constant for all available lung units for ventilation. Amato et al. in their study also postulated that the influence of tidal ventilation could be measured in a better way if $\mathrm{V}_{\mathrm{T}}$ can be normalized to $\mathrm{C}_{\mathrm{RS}}$ instead of PBW. This is suggesting that the ratio of $\mathrm{V}_{\mathrm{T}} / \mathrm{C}_{\mathrm{RS}}$ be a surrogate to the lung dynamic strain; although, $\mathrm{V}_{\mathrm{T}}$ according to the PBW could be imprecise as the available lung volume is variable with the severity of ARDS.

It is worth mentioning that there is a relationship between the airway DP (Pplat-PEEP) and transpulmonary DP (Airway Pplat-PEEP and esophageal plateau - end-expiratory esophageal pressure). Taking into consideration the chest wall elastance, such a variable can positively quantify lung stress, which may be a harmless strategy to modify MV support. ${ }^{[16,17]}$ This is certainly true in the case of minimal to huge overestimation of transpulmonary pressure such as in patients who are underweight, have pneumonia, morbid obesity, and increased intra-abdominal pressure. Indeed, transpulmonary DP is certainly less than the airway DP in patients who are sedated in the absence of spontaneous breathing efforts. ${ }^{[18]}$ For that reason, adjusting $\mathrm{V}_{\mathrm{T}}$ according to the available lung units by calculating DP instead of IBW could lead to a better protective lung strategy in ARDS patients. ${ }^{[14,15]}$

\section{Factors Influencing Driving Pressure Measurements}

For patients who are deeply sedated and mechanically ventilated with no obvious dynamic hyperinflation, DP is defined as Pplateau - PEEP, which equals $V_{T}$ to $C_{R S}$ ratio. Indeed, DP basically reveals the degree of lung stretch during the delivery of a single breath. ${ }^{[19]}$ Studies reported that lowering the DP by adjusting the ventilator parameters has a strong relationship with associated clinical outcome and survival; modifications in $\mathrm{V}_{\mathrm{T}}, \mathrm{V}_{\mathrm{T}}$ calculated by PBW, Pplat, or PEEP influenced the overall clinical outcome only when there is a change in DP. ${ }^{[14]}$

DP is obviously affected by chest wall elastance, which may grossly vary amongst patients. Therefore, meticulous attention has to be given while assessing DP to estimate the lung properties. The effect of reformed elastic properties of the chest wall on distending pressure may be crucial in such cases. ${ }^{[16]}$ During controlled MV in the absence of spontaneous breathing efforts, the inspiratory muscle pressure (Pmus) is considered to be zero, and it should not interfere in the measurement of DP. ${ }^{[20]}$

Measuring the DP on an assisted/spontaneously breathing patient on mechanical ventilator may not be accurate as compared to controlled ventilation. Airway pressure delivered by a ventilator throughout assisted breaths is always less compared to a fully controlled breath delivery. Physiologically there is a massive fluctuation in the transpulmonary pressure during any spontaneous effort because of a forceful inspiratory effort, which may contribute to show diverse values. ${ }^{[20]}$ However, when DP is measured from the Pplat when the flow is not zero, dynamic transpulmonary pressure reflects the elastic properties of the chest wall as well as the resistance from the airways. This is evidence that the airway resistance considerably varies with changes in flow, which will affect the DP measurement to a certain extent. ${ }^{[2]]}$ In the course of an assisted breath, the patient makes a portion of the total work done for breathing; hence the measured Pplat may limit the indirect measurement of transpulmonary pressure.

Currently available studies show Pplat was calculated at $0.5 \mathrm{~s}$ after the beginning of the end-inspiratory pause phase in the ARMA trial, ${ }^{[1]}$ while the PEEP used was the set PEEP rather the total PEEP. Correspondingly, those studies did not embrace 
the slow decline in airway pressure at the end of inspiratory pause and the auto-PEEP. ${ }^{[22]}$ In addition, a high respiratory rate may cause auto-PEEP because of shorter expiratory time. Therefore, the calculated DP from set PEEP may lead to overestimation of the actual DP of the lungs. Moreover, the presence of a leak, whether in the ventilator system or around the tube, and patients with air leak syndromes may raise the difference between actual DP and measured DP.

The gradual rise of DP seems to be more imperative than the maximum plateau pressure applied, and the possible occurrence of damage by cycling determines overall tissue damage. ${ }^{[14,23]}$ The ventilator flow rate, method of delivery and clinically regulated variables (often not well thought out in the lung-protective strategy) have also been shown to be influential even if the plateau and DPs remain constant. ${ }^{[24,25]}$ Ultimately, the DP measurements will be extensively influenced by the method in which Pplat and PEEP are measured.

\section{Factors Limiting Driving Pressure}

Bedside measurement of DP has emerged as a reliable and modest tool in understanding the prognosis and response to the treatment in the management of critically ill patients on mechanical ventilators. Recent studies support limiting DP below or equal to $14 \mathrm{cmH}_{2} \mathrm{O}$ to have a significant role in minimizing VILI and resulting in a better outcome. ${ }^{[14]}$

There are different strategies to limit DP during MV in ARDS patients; PEEP is given the priority among them. To assess the balance between opening, closing and overdistention during the mechanical breath, it has been suggested that DP is measured at different levels of PEEP. ${ }^{[14]}$ Thus, if PEEP is increased during constant $\mathrm{V}_{\mathrm{T}}$ and $\mathrm{DP}$ reduces, this indicates that there is an increase in the $\mathrm{C}_{\mathrm{RS}}$ and that the higher PEEP is recruiting more number of nonaerated lung units. Similarly, if the DP increases and the $\mathrm{C}_{\mathrm{RS}}$ decrease with an increase in PEEP, it suggests that increased PEEP is causing overdistention of the aerated lung units. ${ }^{[26]}$ Therefore, titrating PEEP to reduce DP may allow the clinician to minimize further injury to the lung due to MV.

Spontaneous breathing effort and asynchrony are commonly seen in mechanically ventilated patients with ARDS due to a couple of known associated complications. Paralyzing and deep sedation favors these patients during the initial stage, which causes a significant reduction in transpulmonary pressure and improvement in outcome. ${ }^{[27]}$ There is no clear evidence to prove the crucial role of these strategies in the measurement of DP. However, it has been known that sedating and paralyzing the patients on a mechanical ventilator could enhance the protective lung ventilation in the early phase of ARDS progression. ${ }^{[28]}$

There is an indirect correlation with reduction of DP and associated and neglected areas in airway management such as proper airway conditioning and $\mathrm{CO}_{2}$ clearance. Presence of dead space, whether physiological or mechanical, will reduce alveolar ventilation fraction of the delivered volume, and this reduction is crucial in washing out $\mathrm{CO}_{2}$, especially with a low $\mathrm{V}_{\mathrm{T}}$ strategy in ARDS management. There are airway adjuncts that could increase or decrease dead space such as heat moisture exchangers (HMEs) and heated wire humidifiers. This has been shown in the literature. In comparison with HMEs, one study found that heated humidifiers permit a reduction in $\mathrm{V}_{\mathrm{T}}$ and Pplat without any variations in $\mathrm{CO}_{2}$ as a result of decreasing the dead space by the heated wire humidifiers. ${ }^{[29]}$ As a result of eliminating this dead space, the plateau pressure decreased and subsequently the DP. This reduction was not found to be due to the increase in PEEP (DP = Pplat-PEEP) since it was maintained at a constant level throughout the study. In addition, applying longer inspiratory pause promotes $\mathrm{CO}_{2}$ washout by enhancing diffusion as well as time for gas exchange. This pause reduces dead space and permits further washout of $\mathrm{CO}_{2}$ which permits decreasing the $\mathrm{V}_{\mathrm{T}}$, and ultimately the DP. ${ }^{[30,31]}$ Figure 1 shows suggested flow diagram for the measurement and titration of DP in mechanically ventilated patients.

\section{Measuring Driving Pressure in Nonacute Respiratory Distress Syndrome Patients}

A recent study published by Marcello et al. measuring DP in non-ARDS patients proved that there is no significant correlation between limiting DP and mortality. The possible reasons for these findings are: (a) Measuring the DP in ARDS

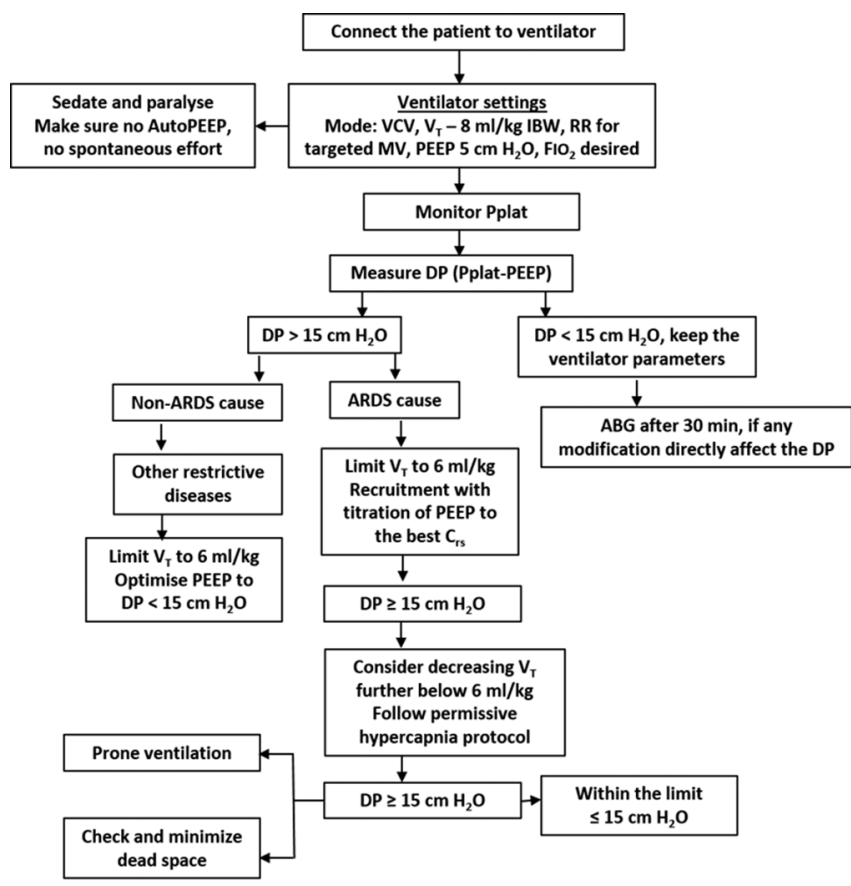

Figure 1: Proposed flow diagram for the measurement and titration of driving pressure in mechanically ventilated patients. VCV - Volume controlled ventilation, $\mathrm{V}_{\mathrm{T}}$ - Tidal volume, IBW - Ideal body weight, RR - Respiratory rate, MV - Minute ventilation, PEEP - Positive end-expiratory pressure, $\mathrm{FIO}_{2}$ - Fraction of inspired oxygen concentration, Crs - Respiratory system compliance; Pplat - Plateau airway pressure, ARDS - Acute respiratory distress syndrome, ABG - Arterial blood gas analysis 
is done for normalizing the $\mathrm{V}_{\mathrm{T}}$ for the $\mathrm{C}_{\mathrm{RS}}$ or to the available lung units for ventilation. This reduction in $\mathrm{C}_{\mathrm{RS}}$ and $\mathrm{V}_{\mathrm{T}}$ in ARDS patients limits the tidal hyperinflation and prevents VILI. However, there is a paucity of evidence by literature to show the relationship between $\mathrm{C}_{\mathrm{RS}}$ and $\mathrm{V}_{\mathrm{T}}$ during $\mathrm{MV}$ and mortality in non-ARDS patients. (b) A relatively low PEEP and shorter time of ventilation assistance, early weaning and extubation also may be associated factors that contribute to the inability to demonstrate reduction of mortality in non-ARDS patients despite the effects on DP. Marcello et al. study also reveal less association between DP and mortality in those patients who have PF ratio $>300$, but DP significantly affects patients who have a PF ratio $<300$. It is worth mentioning that their study is the first to explore the relationship between DP and mortality in non-ARDS patients and hence, their findings should be interpreted with caution.

\section{Current Evidence for the Use of Driving Pressure in Critical Care Units}

The relationship between DP and patient outcomes regarding mortality was first identified by Estenssoro et al. in 2002. They prospectively observed 235 ARDS patients, and their results showed that at the $1^{\text {st }}$ week, DP was an independent variable that consistently differentiated between patients who survived or who have poor outcomes besides other physiological indicators, for instance, $\mathrm{PF}$ ratio. ${ }^{[32]}$

The first serious discussions and analyses of DP emerged in 2013 by Amato et al. with the meta-analysis of nine prospective trials that involved 3500 ARDS patients. The most striking results to emerge from this data was that DP was found as an independent paramount factor that associated with ARDS survivors. Interestingly, this correlation existed although the parameters of MV were strictly manipulated by following protective ventilation strategies such as limiting the $\mathrm{V}_{\mathrm{T}}$ to $<6 \mathrm{ml} / \mathrm{kg}$ of PBW and Pplateau $<30 \mathrm{cmH}_{2} \mathrm{O}^{[14]}$

Turning now to the experimental evidence on measuring DP and by the results from Amato et al., further studies have proved that DP is strongly associated with the mortality rate in ARDS patients. ${ }^{[14,18,33]}$ They found that using PEEP titration to limit the adverse effects of increased transpulmonary pressures significantly benefits both respiratory system elastance and DP. Thereby, they concluded that implementation strategies to reduce the transpulmonary and respiratory system DP in the initial phase of managing ARDS patients would improve patients' survival rate. Similarly, other randomized controlled trials (RCTs) in ARDS patients have revealed that DP is an associated risk factor for increased hospital mortality beside $\mathrm{C}_{\mathrm{RS}}$ and Pplat. ${ }^{[34-36]}$ Recently in 2017, Villar et al. studied 778 patients who identified patients with moderate to severe ARDS to evaluate the associated risk factors of mortality based on MV settings such as $\mathrm{V}_{\mathrm{T}}$, PEEP, Pplat, and DP. Their findings revealed that measuring the Pplat correlated better with mortality than DP in patients undergoing MV with protective lung strategies. The identified cut-off values for both Pplat and DP at the risk of increased death were 29 and $19 \mathrm{~cm} \mathrm{H}_{2} \mathrm{O}$, respectively. ${ }^{[37]}$

In one of the largest multinational, observational studies conducted on 2377 patients with ARDS and admitted in 52 ICUs, DP was associated with higher mortality rather than $\mathrm{V}_{\mathrm{T}}$ in patients with moderate-to-severe ARDS. ${ }^{[1]}$ Interestingly, their result reported that limiting DP with other risk factors such as active neoplasm, hematologic neoplasm, and chronic liver failure could decrease mortality and improve outcomes. ${ }^{[38]}$

An RCT published by Cavalcanti et al. offers some important insights into the management of ARDS and recruitment strategies to minimize VILI by titrating the PEEP and limiting the DP. ${ }^{[39]}$ They found that lung recruitment and titrated PEEP strategy as compared to low PEEP increased mortality. The possible explanations for such results were initially thought to be physiological side-effects of lung recruitment and PEEP, such as hemodynamic instability and overstretched lung units even though DP was reduced. Second, as a result of using low $\mathrm{V}_{\mathrm{T}}$ strategy in the controlled group, DP was decreased, which resulted in lower mortality compared with the interventional group. The last possible explanation for their findings is the breath stacking phenomenon which was caused by an inadvertently higher $\mathrm{V}_{\mathrm{T}}$ delivery compared to the set $\mathrm{V}_{\mathrm{T}}$. This effect was similar in both arms but might have caused more over-distention in the higher PEEP group.

\section{CONCLUSION}

Measuring the DP for adjusting the ventilator parameters (especially the $\mathrm{V}_{\mathrm{T}}$ ) is a remarkable clinical change that warrants more investigations. Obviously, lung volumes vary grossly in diverse patient groups depending on their sex, height and certainly altered pathologic progressions in disease as well as their distinct characteristics of the chest as a whole. Previous studies strongly supported the use of low $\mathrm{V}_{\mathrm{T}}$ and a moderate amount of applied PEEP levels to reduce VILI, probably due to a reduction in DP thereby, less possibility of overdistention of the alveoli. The current data highlight the importance of limiting the DP to $<14 \mathrm{cmH}_{2} \mathrm{O}$, while accepting the fact that identifying a properly targeted DP in an individual patient is a real challenge. Measuring DP and adjusting the $\mathrm{V}_{\mathrm{T}}$ accordingly in ARDS patients may be a good strategy for reduction in mortality. However, in non-ARDS patients, there is a paucity of evidence to explore the relationship between DP and mortality rate in this patient group. Considerably more work will need to be done through randomized controlled clinical trials to assess the ventilator changes required to achieve an ideal DP level. Such an investigation would help to determine whether our observations could be translated into clinical changes that may be implemented at the bedside.

\section{Financial support and sponsorship}

Nil.

\section{Conflicts of interest}

There are no conflicts of interest. 


\section{REFERENCES}

1. Bellani G, Laffey JG, Pham T, Fan E, Brochard L, Esteban A, et al. Epidemiology, patterns of care, and mortality for patients with acute respiratory distress syndrome in Intensive Care Units in 50 countries. JAMA 2016;315:788-800.

2. ARDS Definition Task Force, Ranieri VM, Rubenfeld GD, Thompson BT, Ferguson ND, Caldwell E, et al. Acute respiratory distress syndrome: The berlin definition. JAMA 2012;307:2526-33.

3. Gattinoni L, Marini JJ, Pesenti A, Quintel M, Mancebo J, Brochard L, et al. The "baby lung" became an adult. Intensive Care Med 2016;42:663-73.

4. Webb HH, Tierney DF. Experimental pulmonary edema due to intermittent positive pressure ventilation with high inflation pressures. Protection by positive end-expiratory pressure. Am Rev Respir Dis 1974;110:556-65.

5. Dreyfuss D, Saumon G. Ventilator-induced lung injury: Lessons from experimental studies. Am J Respir Crit Care Med 1998;157:294-323.

6. Tremblay L, Valenza F, Ribeiro SP, Li J, Slutsky AS. Injurious ventilatory strategies increase cytokines and c-fos m-RNA expression in an isolated rat lung model. J Clin Invest 1997;99:944-52.

7. Greenfield LJ, Ebert PA, Benson DW. Effect of positive pressure ventilation on surface tension properties of lung extracts. Anesthesiology 1964;25:312-6.

8. Muscedere JG, Mullen JB, Gan K, Slutsky AS. Tidal ventilation at low airway pressures can augment lung injury. Am J Respir Crit Care Med 1994;149:1327-34.

9. Dreyfuss D, Soler P, Basset G, Saumon G. High inflation pressure pulmonary edema. Respective effects of high airway pressure, high tidal volume, and positive end-expiratory pressure. Am Rev Respir Dis 1988;137:1159-64.

10. Slutsky AS, Ranieri VM. Ventilator-induced lung injury. N Engl J Med 2013;369:2126-36.

11. Acute Respiratory Distress Syndrome Network, Brower RG, Matthay MA, Morris A, Schoenfeld D, Thompson BT, et al. Ventilation with lower tidal volumes as compared with traditional tidal volumes for acute lung injury and the acute respiratory distress syndrome. N Engl J Med 2000;342:1301-8.

12. Terragni PP, Rosboch G, Tealdi A, Corno E, Menaldo E, Davini $\mathrm{O}$, et al. Tidal hyperinflation during low tidal volume ventilation in acute respiratory distress syndrome. Am J Respir Crit Care Med 2007; 175:160-6.

13. Gattinoni L, Pesenti A. The concept of "baby lung". Intensive Care Med 2005;31:776-84.

14. Amato MB, Meade MO, Slutsky AS, Brochard L, Costa EL, Schoenfeld DA, et al. Driving pressure and survival in the acute respiratory distress syndrome. N Engl J Med 2015;372:747-55.

15. Goligher EC, Ferguson ND, Brochard LJ. Clinical challenges in mechanical ventilation. Lancet 2016;387:1856-66.

16. Chiumello D, Carlesso E, Brioni M, Cressoni M. Airway driving pressure and lung stress in ARDS patients. Crit Care 2016;20:276.

17. Cortes-Puentes GA, Gard KE, Adams AB, Faltesek KA, Anderson CP, Dries DJ, et al. Value and limitations of transpulmonary pressure calculations during intra-abdominal hypertension. Crit Care Med 2013;41:1870-7.

18. Talmor D, Sarge T, Malhotra A, O'Donnell CR, Ritz R, Lisbon A, et al. Mechanical ventilation guided by esophageal pressure in acute lung injury. N Engl J Med 2008;359:2095-104.

19. Vaporidi K, Xirouchaki N, Georgopoulos D. Should we care about driving pressure during assisted mechanical ventilation? J Intensive Crit Care 2017;3:2.

20. Mauri T, Langer T, Zanella A, Grasselli G, Pesenti A. Extremely high transpulmonary pressure in a spontaneously breathing patient with early severe ARDS on ECMO. Intensive Care Med 2016;42:2101-3.

21. Mauri T, Grasselli G, Suriano G, Eronia N, Spadaro S, Turrini C, et al. Control of respiratory drive and effort in extracorporeal membrane oxygenation patients recovering from severe acute respiratory distress syndrome. Anesthesiology 2016;125:159-67.

22. Barberis L, Manno E, Guérin C. Effect of end-inspiratory pause duration on plateau pressure in mechanically ventilated patients. Intensive Care Med 2003;29:130-4.

23. Hotchkiss JR Jr., Blanch L, Murias G, Adams AB, Olson DA, Wangensteen OD, et al. Effects of decreased respiratory frequency on ventilator-induced lung injury. Am J Respir Crit Care Med 2000;161:463-8.

24. Protti A, Maraffi T, Milesi M, Votta E, Santini A, Pugni P, et al. Role of strain rate in the pathogenesis of ventilator-induced lung edema. Crit Care Med 2016;44:e838-45.

25. Maeda Y, Fujino Y, Uchiyama A, Matsuura N, Mashimo T, Nishimura M, et al. Effects of peak inspiratory flow on development of ventilator-induced lung injury in rabbits. Anesthesiology 2004;101:722-8.

26. Sahetya SK, Goligher EC, Brower RG. Fifty years of research in ARDS. Setting positive end-expiratory pressure in acute respiratory distress syndrome. Am J Respir Crit Care Med 2018;197:684-5.

27. Papazian L, Forel JM, Gacouin A, Penot-Ragon C, Perrin G, Loundou A, et al. Neuromuscular blockers in early acute respiratory distress syndrome. N Engl J Med 2010; 363:1107-16.

28. Beitler JR, Sands SA, Loring SH, Owens RL, Malhotra A, Spragg RG, et al. Quantifying unintended exposure to high tidal volumes from breath stacking dyssynchrony in ARDS: The BREATHE criteria. Intensive Care Med 2016;42:1427-36.

29. Morán I, Bellapart J, Vari A, Mancebo J. Heat and moisture exchangers and heated humidifiers in acute lung injury/acute respiratory distress syndrome patients. Effects on respiratory mechanics and gas exchange. Intensive Care Med 2006;32:524-31.

30. Devaquet J, Jonson B, Niklason L, Si Larbi AG, Uttman L, Aboab J, et al. Effects of inspiratory pause on $\mathrm{CO} 2$ elimination and arterial $\mathrm{PCO} 2$ in acute lung injury. J Appl Physiol (1985) 2008;105:1944-9.

31. Aguirre-Bermeo $\mathrm{H}$, Morán I, Bottiroli $\mathrm{M}$, Italiano $\mathrm{S}$, Parrilla FJ, Plazolles E, et al. End-inspiratory pause prolongation in acute respiratory distress syndrome patients: Effects on gas exchange and mechanics. Ann Intensive Care 2016;6:81.

32. Estenssoro E, Dubin A, Laffaire E, Canales H, Sáenz G, Moseinco M, et al. Incidence, clinical course, and outcome in 217 patients with acute respiratory distress syndrome. Crit Care Med 2002;30:2450-6.

33. Baedorf Kassis E, Loring SH, Talmor D. Mortality and pulmonary mechanics in relation to respiratory system and transpulmonary driving pressures in ARDS. Intensive Care Med 2016;42:1206-13.

34. Guérin C, Reignier J, Richard JC, Beuret P, Gacouin A, Boulain T, et al. Prone positioning in severe acute respiratory distress syndrome. N Engl J Med 2013;368:2159-68.

35. Papazian L, Forel JM, Gacouin A, Penot-Ragon C, Perrin G, Loundou A, et al. Neuromuscular blockers in early acute respiratory distress syndrome. N Engl J Med 2010;363:1107-16.

36. Guérin C, Papazian L, Reignier J, Ayzac L, Loundou A, Forel JM, et al. Effect of driving pressure on mortality in ARDS patients during lung protective mechanical ventilation in two randomized controlled trials. Crit Care 2016;20:384.

37. Villar J, Martín-Rodríguez C, Domínguez-Berrot AM, Fernández L, Ferrando C, Soler JA, et al. A quantile analysis of plateau and driving pressures: Effects on mortality in patients with acute respiratory distress syndrome receiving lung-protective ventilation. Crit Care Med 2017;45:843-50

38. Laffey JG, Bellani G, Pham T, Fan E, Madotto F, Bajwa EK, et al. Potentially modifiable factors contributing to outcome from acute respiratory distress syndrome: The LUNG SAFE study. Intensive Care Med 2016;42:1865-76.

39. Writing Group for the Alveolar Recruitment for Acute Respiratory Distress Syndrome Trial (ART) Investigators, Cavalcanti AB, Suzumura ÉA, Laranjeira LN, Paisani DM, Damiani LP, et al. Effect of lung recruitment and titrated positive end-expiratory pressure (PEEP) vs. low PEEP on mortality in patients with acute respiratory distress syndrome: A Randomized clinical trial. JAMA 2017;318:1335-45. 